\title{
Peluang Pelaksanaan dan Tantangan Pengembangan Hospital without Walls pada Pelayanan Kebidanan dan Kandungan di RSUD Noongan
}

\author{
Mario L. Mewengkang, ${ }^{1}$ Gustaaf A. E. Ratag, ${ }^{2}$ Jimmy Posangi ${ }^{3}$
}

\author{
${ }^{1}$ Program Studi Ilmu Kesehatan Masyarakat, Pascasarjana Universitas Sam Ratulangi, \\ Manado, Indonesia \\ ${ }^{2}$ Bagian Ilmu Kedokteran Komunitas Fakultas Kedokteran Universitas Sam Ratulangi, \\ Manado, Indonesia \\ ${ }^{3}$ Bagian Farmakologi Fakultas Kedokteran Universitas Sam Ratulangi, Manado, Indonesia \\ Email: mewengkangmario2@gmail.com
}

\begin{abstract}
Hospitals as the health referral facilities play an important role in decreasing the maternal mortality rate (MMR) since they also belong to the personal health service as a whole including mother child health care. This study was aimed to analyze the implementation opportunities and challenges of developing 'hospital without walls' program in obstetrics and gynaecology services at RSUD (Rumah Sakit Umum Daerah) Noongan. This was a qualitative study. Informants in this study were taken from three places, as follows: the hospital, namely the Director of the Hospital and obstetrician-gynaecologist doctors; puskesmas (primary health center), namely the heads of puskesmas; and the community. Data were collected through in-depth interviews and direct observation. The results indicated that 'hospital without walls' in obstetrics and gynaecology services at RSUD Noongan had the opportunity to be implemented because this program had been partly applied by the hospital and it had a good impact on the hospital, health center, and the community as well as PONED-PONEK collaboration. The challenges of implementing this program at RSUD Noongan were the existence of cold cases caused by gatekeeper failure, lack of health facilities and human resources at the puskesmas, and insubstantial collaboration between PONED-PONEK. In conclusion, 'hospital without walls' program in obstetrics and gynaecology services can be implemented at RSUD Noongan with awareness to the possible challenges in its development.
\end{abstract}

Keywords: opportunity and challenge; hospital without walls; obstetrics and gynecology services

\begin{abstract}
Abstrak: Rumah sakit sebagai fasilitas kesehatan rujukan paripurna berperan penting dalam menurunkan angka kematian ibu (AKI) termasuk pelayanan kesehatan ibu dan anak (KIA). Penelitian ini bertujuan untuk menganalisis peluang pelaksanaan dan tantangan pengembangan program hospital without walls pada pelayanan kebidanan dan kandungan di RSUD Noongan. Jenis penelitian ialah kualitatif. Informan penelitian diambil dari tiga tempat yaitu: RSUD Noongan (Direktur Rumah Sakit dan dokter spesialis obstetri dan ginekologi); puskesmas (kepala puskesmas); dan masyarakat. Data dikumpulkan melalui wawancara mendalam dan observasi langsung. Hasil penelitian memperlihatkan bahwa hospital without walls pada pelayanan kebidanan dan kandungan di RSUD Noongan berpeluang untuk dilaksanakan karena sebagian program ini telah diterapkan oleh rumah sakit dan juga berdampak baik bagi rumah sakit, puskesmas dan masyarakat, serta kolaborasi PONED-PONEK. Tantangan pelaksanaan program ini di RSUD Noongan yaitu adanya cold case yang merupakan kegagalan gatekeeper, fasilitas kesehatan dan sumber daya manusia (SDM) yang masih kurang di puskesmas, serta kolaborasi PONED-PONEK belum optimal. Simpulan penelitian ini ialah program hospital without walls pada pelayanan kebidanan dan kandungan berpeluang untuk dilaksanakan di RSUD Noongan dengan memperhatikan tantangan pengembangan.
\end{abstract}

Kata kunci: peluang dan tantangan; hospital without walls; pelayanan kebidanan dan kandungan 


\section{PENDAHULUAN}

Tahun 2015 merupakan tahun evaluasi capaian Millennium Development Goals (MDGs). Indonesia tidak berhasil mencapai 102 per 100.000 kelahiran hidup walaupun telah terjadi kecenderungan penurunan angka kematian ibu (AKI) yaitu selama periode 1991 sampai 2015 dilaporkan penurunan AKI dari 390 menjadi 305 per 100.000 kelahiran hidup. Penyebab kematian ibu pada tahun 2020 sebagian besar disebabkan oleh pendarahan yaitu sebanyak 1.330 kasus; hipertensi dalam kehamilan sebanyak 1.110 kasus; dan gangguan sistem peredaran darah sebanyak 230 kasus dengan jumlah kematian ibu saat itu sebesar 4.627 kematian di Indonesia. Upaya percepatan penurunan AKI antara lain menjamin setiap ibu mampu mengakses pelayanan kesehatan ibu yang berkualitas antara lain pelayanan kesehatan ibu hamil, persalinan yang ditolong oleh tenaga kesehatan yang kompeten di fasilitas kesehatan, perawatan setelah melahirkan bagi ibu hamil, serta perawatan khusus dan rujukan jika terdapat penyulit dan pelayanan kontrasepsi setelah melahirkan. ${ }^{1}$

Pelayanan Obstetri Neonatal Emergensi Komprehensif (PONEK) di Rumah Sakit merupakan bentuk upaya penyediaan pelayanan bagi ibu dan bayi baru lahir secara terpadu dengan tujuan yaitu menurunkan AKI dan Angka Kematian Bayi $(\mathrm{AKB}){ }^{2}$ Penelitian yang dilakukan oleh Jaya et $\mathrm{al}^{3}$ menyatakan bahwa keberadaan PONEK dan Pelayanan Obstetrik dan Neonatal Emergensi Dasar (PONED) sangat membantu menurunkan AKI bila disertai petugas kesehatan serta sarana dan prasarana yang memadai. PONED dan PONEK harus bekerjasama untuk saling mendukung pelayanan ibu dan bayi sebaik mungkin.

Puskesmas sebagai gatekeeper sering terkendala oleh kompetensi petugas kesehatan yang lemah, kurangnya penguasaan penanganan 144 pedoman praktek klinik kasus di layanan primer atau puskesmas, dan belum mantapnya pelaksanaan pengembangan dokter spesialis kedokteran layanan primer. Peran fasilitas kesehatan primer sebagai gatekeeper belum berjalan dengan baik. Data menunjukkan tingginya jumlah fasilitas kesehatan primer yang merujuk ke rumah sakit yaitu sekitar $17 \%$ sedangkan idealnya maksimal angka rujukan fasilitas pelayanan kesehatan (fasyankes) primer ke rumah sakit tidak boleh melebihi $10 \% .^{4}$

Penelitian oleh Ramadhani ${ }^{5}$ menunjukkan bahwa tingginya angka rujukan puskesmas disebabkan oleh rendahnya kualitas dan kuantitas sumber daya manusia (SDM) di puskesmas, tidak adanya standar operasional prosedur (SOP), minimnya sarana dan prasarana yang lengkap dan memadai, indikasi medis dari pasien di luar kemampuan puskesmas, ketidaklengkapan obat-obatan dan bahan medis, serta kurangnya pemahaman pasien terhadap sistem rujukan.

Masalah-masalah yang dipaparkan menjadi peluang bagi rumah sakit untuk ikut berperan mengatasinya. Upaya dalam meningkatkan derajat kesehatan masyarakat seperti kesehatan ibu harus dilaksanakan secara menyeluruh melalui upaya promotif, preventif, kuratif, dan rehabilitatif. Rumah sakit yang selama ini hanya berfokus pada pelayanan kuratif dan rehabilitatif diharapkan bekerja sama dengan puskesmas untuk turut menjangkau masyarakat dalam memberikan pelayanan promotif dan prefentif. Program ini sudah dilaksanakan oleh Pemerintah Jawa Tengah dan menjadi program unggulan yaitu Program Rumah Sakit Tanpa Dinding (hospital without walls). ${ }^{6}$

Pelayanan kebidanan dan kandungan di RSUD Noongan mengacu pada Standar Pelayanan Minimal Rumah Sakit yang tertuang pada Kepmenkes Nomor: 129/ Menkes/SK/II/2008 yaitu dilayani oleh dokter spesialis obstetri ginekologi mulai dari pelayanan rawat jalan kebidanan dan kandungan sampai ruang rawat maternal. Pasien mendapat pelayanan konsultasi, pemeriksaan fisik lengkap, laboratorium, pemeriksaan penunjang lainnya, persalinan normal dan penyulit bahkan tindakan operasi bagi ibu hamil dengan penyulit dan pasien dengan penyakit ginekologi. Pasien kebidanan dan kandungan dengan penyulit yang tidak dapat ditangani di RSUD Noongan, akan di rujuk ke rumah sakit yang lebih mampu. RSUD Noongan juga menerima rujukan pasien kebidanan dan kan- 
dungan dari puskesmas atau puskesmas satelit sesuai sistem rujukan yang ditetapkan oleh Gubernur Sulawesi Utara. ${ }^{7}$

Hospital without walls dalam pelayanan kebidanan dan kandungan berpeluang untuk dilaksanakan karena kolaborasi PONEDPONEK dimungkinkan dan diharapkan untuk menurunkan angka kematian ibu. Data Bappenas 2019 menyatakan bahwa peran puskesmas sebagai gatekeeper belum berjalan dengan baik dimana terdapat angka rujukan masih tinggi karena keterbatasan SDM, sarana prasarana dll. Peran rumah sakit sebagai sumber tenaga ahli dibutuhkan agar pelaksanaan rujukan puskesmas PONED yang sesuai standar bisa tercapai. ${ }^{4}$

Peluang lain dari kegiatan ini ialah pelayanan kesehatan terintegrasi yang dilakukan oleh beberapa rumah sakit di Indonesia dimana pelayanan kesehatan diberikan di rumah pasien sudah terbukti efektif dalam menurunkan angka kematian dan angka kesakitan. Pelayanan obstetri dan ginekologi sosial yang merupakan pengembangan obstetri dan ginekologi yang tatalaksananya mengikutsertakan usaha pencegahan sehingga ikut serta memperhitungkan faktor lingkungan yang berkaitan dengan fenomena kematian maternal dan perinatal serta penyakit alat reproduksi wanita. Diperlukan pendidikan khusus atau wawasan seorang klinisi diperluas, sehingga dapat dihasilkan klinisi obstetri dan ginekologi konsultan yang mempunyai kompetensi memberikan konsultasi untuk menyelesaikan masalah kesehatan reproduksi secara individual serta dalam masyarakat secara holistik, paripurna, dan terintegrasi. ${ }^{8}$

Tantangan pengembangan program hospital without walls pada pelayanan kebidanan dan kandungan dapat berupa AKI masih tinggi, angka rujukan masih tinggi, SDM di puskesmas masih kurang baik (kuantitas maupun kualitas), keterbatasan sarana dan prasarana puskesmas, dan kolaborasi PONED-PONEK yang belum optimal. Tantangan ini berdasarkan data Badan Perencanaan Pembangunan Nasional (Bappenas) dan penelitian-penelitian yang telah dilakukan sebelumnya.

\section{METODE PENELITIAN}

Penelitian ini menggunakan metode penelitian kualitatif. Informan pada penelitian ini didasarkan pada prinsip kesesuaian (approppiateness) dan kecukupan (adequacy). Berdasarkan prinsip tersebut yang menjadi informan dalam penelitian diambil dari 3 (tiga) tempat yaitu rumah sakit terdiri dari Direktur Rumah Sakit (Informan A), dokter spesialis obstetri dan ginekologi (Informan B); puskesmas yaitu kepala puskesmas Towuntu Timur (Informan C) dan Tumaratas (Informan D); dan juga masyarakat (Informan E, yaitu pasien yang pernah berobat ke RSUD Noongan). Data yang dikumpulkan dalam penelitian ini diperoleh melalui wawancara mendalam dan observasi langsung.

\section{HASIL PENELITIAN}

Peluang pelaksanaan hospital without wall di RSUD Noongan pada pelayanan kebidanan dan kandungan

Program hospital without walls di RSUD Noongan sudah dilaksanakan: Apakah RSUD Noongan sudah menerapkan program hospital without walls?

A) "Kalau pelayanan pengobatan di luar rumah sakit seperti pengobatan cumacuma di masyarakat kita pernah ada. Tapi itu belum menjadi program rutin dari rumah sakit. Kalau ada permintaan seperti itu, yang bersangkutan harus menyurat atau bermohon dulu ke Dinas Kesehatan Provinsi Sulawesi Utara dan jika disetujui, permintaan tersebut diteruskan kepada kami untuk ditindak lanjuti."

B) "Selama saya bekerja di sini, pelayanan kesehatan di luar gedung terutama pelayanan kebidanan dan kandungan belum pernah. Kalau sebatas konsultasi pasien dengan komunikasi via telpon kadang saya berikan nomor telepon saya ke pasien untuk konsultasi."

C) "Selama ini belum ada rumah sakit yang berkolaborasi dengan kami dalam memberikan pelayanan kesehatan ke masyarakat"

D) "Belum pernah"

E) "Saya hanya pernah konsultasi dengan dokter spesialis via telepon, pernah me- 
manfaatkan teman di rumah sakit untuk pendaftaran akan berobat melalui telepon."

Pelaksanaan hospital without walls berdampak baik: Bagaimana dampak pelaksanaan hospital without walls?

A) "Dalam penilaian akreditasi, rumah sakit harus punya inovasi, jika hospital without walls diterapkan, tentu inovasi rumah sakit akan bertambah dan memengaruhi penilaian akreditasi rumah sakit. Angka kunjungan di rumah sakit bisa meningkat karena masyarakat sudah mengenal pelayanan rumah sakit melalui program hospital without walls, yang berdampak pada pendapatan rumah sakit. Menunjang program nasional dengan menurunkan AKI."

B) "Mungkin jumlah kunjungan meningkat terutama kasus-kasus dengan penyulit dan menurunkan angka rujukan puskesmas. Paling tidak untuk kasus-kasus kompetensi puskesmas berkurang bahkan tidak muncul lagi di rumah sakit. Koordinasi rumah sakit dan puskesmas dapat terjalin dan akhirnya dapat menurunkan angka kematian ibu."

C) "Rumah sakit dapat membantu puskesmas dalam meningkatkan kapasitas SDM sehingga kami dapat memberikan pelayanan yang baik bagi masyarakat lebih khusus pelayanan kesehatan ibu."

D) "Apapun bentuk kegiatannya pasti dapat membatu puskesmas untuk memberikan pelayanan lebih baik lagi bagi masyarakat."

E) "Pelayanan kesehatan di puskesmas dan rumah sakit menjadi lebih baik."

Kolaborasi PONEK-PONED: Apakah terdapat kerja sama atau kolaborasi program antara PONEK-PONED?

A) "Khusus untuk pelayanan kebidanan dan kandungan dalam hal ini PONEK sudah jalan tapi pelayanan masih di dalam rumah sakit belum bisa di luar rumah sakit. Perkuat dulu pelayanan di rumah sakit baru di luar rumah sakit."

B) "Belum berjalan."

C) "Belum jalan kerjasama atau kolaborasi program. Hanya MOU rujukan secara umum."
D) "Kami memiliki MOU dengan RSUD Noongan hanya tentang rujukan secara umum. Khusus kebidanan dan kandungan belum ada kegiatan."

Tantangan pelaksanaan hospital without walls di RSUD Noongan pada pelayanan kebidanan dan kandungan

Terdapat cold case: Apakah terdapat kasus rujukan kebidanan dan kandungan di rumah sakit yang se harusnya pasien tersebut ditangani di Puskesmas?

A) Masih ada. Biasanya terjadi di UGD pada kasus persalinan normal pasien hendak partus dengan pembukaan lengkap atau kepala sudah di bawah, kami layani. Untuk kasus kebidanan seperti itu."

B) "Masih ada. Misalnya pasien bisa melahirkan normal tapi karena waktu sudah larut malam, pasien mencari rumah sakit terdekat. Di poliklinik juga banyak. Banyak juga kasus karena bidannya masih muda belum pengalaman karena takut, jadi pasiennya dirujuk dengan indikasi yang dibuat seperti ketuban pecah dini. Ada juga kebalikannya, yang seharunya pasien dirujuk tapi ditahan oleh puskesmas. Akhirnya setelah kegawatdaruratan baru datang ke rumah sakit tapi sudah terlambat. Puskesmas PONED biasanya penanganan pasien kandungan sudah bagus. Yang susah kalau puskesmas bukan PONED. Akhirnya AKI di rumah sakit tinggi padahal karena keterlambatan dari puskesmas."

C) "Masih ada, karena kadang kami kekurangan obat, alat kesehatan dan tenaga bidan belum kompeten"

D) "Diusahakan kasus-kasus yang harus kami tangani, ditangani di puskesmas atau rumah singgah, bidan-bidan kami cukup terampil. Kami mengedukasi ibu hamil untuk rajin kontrol di puskesmas jadi hal-hal yang tidak seharusnya terjadi masih sangat sedikit. Pendidikan bidan di sini D4."

Fasilitas kesehatan di puskesmas masih kurang: Bagaimana fasilitas yang ada di puskesmas untuk pelayanan kebidanan dan kandungan?

C) "Untuk fasilitas di puskesmas ya.. masih 
kurang memadai karena kami masih merujuk pasien dengan alasan tidak lengkapnya alat kesehatan dan obatobatan di Puskesmas"

D) "Alat kesehatan untuk pelayanan kesehatan masih kurang di puskesmas kami...."

Sumber daya manusia di puskesmas masih kurang baik kuantitas maupun kualitas: Bagaimana SDM yang ada di puskesmas untuk pelayanan kebidanan dan kandungan?

C) "Kami hanya mempunyai 1 bidan dan 1 dokter yang dilatih PONED. Satu orang perawat dipindahkan ke Puskesmas lain. Saya rasa kurang ya. Diusahakan tiap kali jaga malam terdapat dua bidan, satu dokter dan satu perawat untuk kasus kebidanan dengan penyulit. Kami juga membutuhkan pelatihan/penyegaran tentang PONED.

D) "Jumlah SDM masih kurang".... perlu peningkatan kualitas dari tenaga kesehatan juga dengan adanya bimbingan, pelatihan atau workshop dari dokter spesialis."

Kolaborasi PONED-PONEK belum optimal: Apakah pernah koordinasi sehubungan dengan rujukan pasien kebidanan dan kandungan?

A) "Belum pernah"

B) "Belum pernah"

C) "Belum pernah, kami hanya membuat perjanjian kerja sama meyangkut rujukan pasien secara umum."

D) "Belum pernah"

\section{BAHASAN}

Peluang program hospital without walls merupakan kesempatan yang ada ataupun dimiliki oleh pemegang program hospital without walls, dalam hal ini pemegang program ialah RSUD Noongan. Terdapat beberapa peluang yang dimiliki RSUD Noongan pada pelayanan kebidanan dan kandungan dalam melaksanakan hospital without walls, yaitu: program hospital without walls di RSUD Noongan sudah dilaksanakan (sebagian); pelaksanaan hospital without walls berdampak baik; dan kolaborasi PONEK-PONED

Hasil wawancara yang dilakukan menyatakan bahwa terdapat penerapan hospital without walls pada pelayanan kesehatan di RSUD Noongan yaitu pengobatan cuma-cuma di masyarakat yang melibatkan berbagai jenis tenaga kesehatan di rumah sakit, konsultasi dokter spesialis lewat telepon dan pendaftaran pasien melalui telepon walaupun kegiatan-kegiatan ini belum menjadi program rumah sakit. Hal ini menunjukkan bahwa program hospital without walls berpeluang untuk dilaksanakan di RSUD Noongan. Peluang pelaksanaan hospital without walls sudah diteliti di beberapa rumah sakit di Sulawesi Utara yaitu di RS Bethesda Tomohon sesuai penelitian dari Waworuntu et $\mathrm{al}^{9}$ pada tahun 2020 dan RSUP Ratatotok Buyat melalui penelitian dari Sumule et al ${ }^{10} 2021$ dengan hasil bahwa program hospital without walls berpeluang diterapkan di kedua rumah sakit tersebut. Hospital without walls menjadi program Pemerintah Provinsi Jawa Tengah dimana program tersebut merupakan perwujudan dari upaya pemerintah daerah Provinsi Jawa Tengah untuk mencapai derajat kesehatan masyarakat setinggi tingginya. ${ }^{11}$ Hospital without walls menjadi salah satu inovasi rumah sakit dalam rangka memenuhi apa yang menjadi tugas rumah sakit yaitu memberikan pelayanan kesehatan yang paripurna bagi masyarakat susuai dengan Undang-Undang RI Nomor 44 Tahun 2009. Pernyataan direktur rumah sakit tentang dapat menyiapkan anggaran jika diperlukan untuk pemberian insentif bagi dokter spesialis jika harus melaksanakan kegiatan dalam program hospital without walls dan kesedian dokter spesialis untuk mendukung program tersebut menjadi modal bagi RSUD Noongan dalam mengembangkan program hospital without walls, ditambah lagi sambutan dan dukungan dari puskesmas dan masyarakat, membuka peluang program tersebut dilaksanakan.

Hasil wawancara tentang dampak pelaksanaan hospital without walls baik di pihak rumah sakit, puskesmas dan masyarakat semuanya berdampak baik. Direktur rumah sakit menyatakan bahwa berpengaruh dalam penilaian akreditasi, angka kunjungan rumah sakit meningkat dan 
meningkatkan pemasukan serta menunjang program nasional. Menurut dokter spesialis, kunjungan meningkat khususnya pasien dengan penyulit, fungsi gatekeeper berjalan dengan baik sehingga menurunkan AKI. Kepala-kepala puskesmas mengatakan bahwa hospital without walls dapat membantu puskesmas dalam meningkatkan SDM mereka sehingga dapat memberikan pelayanan yang lebih baik bagi masyarakat. Hal ini sesuai dengan hasil penelitian dari Waworuntu et $\mathrm{al}^{9}$ yang menyatakan bahwa program hospital without walls dapat memberikan banyak keuntungan bagi rumah sakit melalui promosi pelayanan rumah sakit, peningkatan jumlah kunjungan dan membantu dalam menunjang akreditasi rumah sakit. RSUD dr. Iskak Tulungagung mengukir prestasi di tingkat nasional dan internasional dengan program hospital without walls-nya antara lain MarkPlus Hermawan Kertajaya, Forum Congress and Award International Hospital Federation (IHF) ke-43 di Oman Convention and Exhibition Centre, Muscat pada 8 November 2019 meraih Gold Award. Kuncinya terdapat di New Concept Hospital Management berkarakter low cost, high quality and hospital social responsibility. Implementasinya berada di 'PSC system' (yang juga sudah diadopsi oleh Kemenkes RI menjadi program nasional) berkolaborasi dengan puskesmas, Palang Merah Indonesia (PMI), sarana kesehatan lainnya, serta Masyarakat Peduli Bencana Tulungagung (BaSARTa) dalam sebuah networking, breaking through the hospital wall. ${ }^{12}$

Pada wawancara dengan direktur rumah sakit, dokter spesialis kebidanan dan kandungan, serta puskesmas diperoleh bahwa belum terdapat kerjasama program menyangkut pelayanan kebidanan dan kandungan lebih khusus kolaborasi PONEKPONED. Kementerian Kesehatan RI telah melaksanakan upaya dalam mendukung percepatan penurunan AKI yaitu optimalisasi di tingkat puskesmas melalui PONED dan didukung oleh rumah sakit mampu PONEK dalam satu Collaborative Improvement PONED-PONEK. Adanya komunikasi PONED-PONEK dapat berupa komu- nikasi melalui telepon atau aplikasi pengiriman pesan. Rujukan yang efektif memerlukan komunikasi antar fasilitas. Proses komunikasi petugas PONED langsung melakukan komunikasi dengan petugas PONEK, baik untuk konsultasi ataupun mengirimkan pasien. Komunikasi yang dibangun dapat menghindari penolakan pasien ke rumah sakit tujuan dan mempercepat proses penanganan pasien di rumah sakit tujuan. Komunikasi yang baik Puskesmas PONED dan RS PONEK dapat meningkatkan kecepatan pelayanan dan ketersediaan tenaga kesehatan yang lebih kompeten di tempat tujuan sehingga pasien dengan kegawatdaruratan maternal dan neonatal bisa ditangani secara cepat dan juga untuk berkonsultasi mengenai tindakan stabilisasi apa yang bisa dilakukan perujuk guna memperbaiki kondisi pasien hingga ke tempat tujuan rujukan dalam keadaan stabil. ${ }^{13}$ Sekiranya terdapat permasalahan dalam pelayanan rujukan bahkan program kesehatan, program rumah sakit tanpa dinding menciptakan kerja sama antara rumah sakit, dinas kesehatan dan puskesmas untuk mencari solusi atas permasalahan tersebut. ${ }^{11}$ Kolaborasi ini menjadi peluang pelaksanaan hospital without walls dimana didukung juga dengan aturan bahwa rumah sakit diberikan kesempatan melakukan pengembangan pelayanan medik spesialistik dan subspesialistik program kesehatan nasional yang tentu dilaksanakan dengan pedoman masing-masing program kesehatan yang ditetapkan Menteri. ${ }^{14}$

Tantangan pengembangan hospital without walls merupakan rangsangan atau hal-hal yang menggugah tekad RSUD Noongan mengembangkan program hospital without walls. Tantangan program hospital without walls yang dinilai dalam penelitian ini ialah: adanya cold case; fasilitas kesehatan di puskesmas masih kurang; sumber daya manusia di puskesmas masih kurang baik kuantitas maupun kualitas; dan kolaborasi PONEK-PONED belum optimal.

Hasil penelitian ini menyatakan bahwa masih terdapat cold case, yaitu kasus-kasus yang seharusnya ditangani di puskesmas 
tapi masih muncul atau dirujuk di rumah sakit. Hal ini menunjukkan kegagalan gatekeeper dalam menjalankan fungsinya yaitu kontak pertama pelayanan, pelayanan berkelanjutan, pelayanan paripurna, dan koordinasi pelayanan. ${ }^{4}$ Penelitian yang dilakukan oleh Ramadhani ${ }^{5}$ menunjukkan bahwa tingginya angka rujukan puskesmas disebabkan salah satunya oleh rendahnya kualitas dan kuantitas sumber daya manusia di puskesmas. Undang-Undang Nomor 44 Tahun 2009 menyatakan bahwa rumah sakit mempunyai empat fungsi, salah satunya yaitu fungsi penyelenggaraan pendidikan dan pelatihan sumber daya manusia dalam rangka peningkatan kemampuan dalam pemberian pelayanan kesehatan, maka dari itu rumah sakit dapat membantu puskesmas dalam meningkatkan kualitas SDM puskesmas sehinga mampu menangani pasien sesuai 144 pedoman praktek klinik kasus layanan primer dan juga mampu memberikan edukasi kepada masyarakat menyangkut pelayanan yang diberikan puskesmas sehingga hospital without walls dapat menurunkan kejadian cold case.

Hasil penelitian ini menyatakan bahwa fasilitas di puskesmas masih kurang. Puskesmas sebagai mitra utama rumah sakit dalam melaksanakan program PONED harus didukung oleh sarana prasaranan memadai agar dapat memberikan pelayanan emergensi dasar. Hal ini menjadi suatu tantangan bagi RSUD Noongan ketika akan melaksanakan program hospital without walls. Minimal dapat memaksimalkan SDM di puskesmas dan meberikan masukan ke puskesmas bahkan dinas kesehatan untuk memenuhi saranan prasarana untuk pelayanan kesehatan tersebut. Fasilitas merupakan bagian penting dalam pemberian pelayanan kesehatan. Fasilitas yang lengkap dan memadai berpengaruh terhadap pelayanan kesehatan yang diberikan kepada masyarakat baik secara preventif maupun kuratif. Pelayanan yang baik akan memberikan kepuasan bagi masyarakat dalam menerima layanan kesehatan yang diberikan. ${ }^{15}$

Pada penelitian ini didapatkan bahwa sumber daya manusia di puskesmas yang merupakan mitra dari rumah sakit dalam memberikan pelayanan kesehatan yang paripurna masih kurang. Hal ini ditunjukkan dengan jumlah dokter, bidan dan perawat di puskesmas masih kurang, tenaga kesehatan yang dilatih PONED pindah tempat tugas, dan masih perlu peningkatan kapasitas petugas kesehatan tentang PONED. Sumber daya manusia yang belum terpenuhi di puskesmas juga menjadi tantangan bagi RSUD Noongan ke depan untuk melaksanakan hospital without walls. Data Bappenas 2019 mencatat, ketersediaan SDM kesehatan puskesmas masih belum mencukupi dan standar jenis petugas minimal puskesmas masih belum terpenuhi. Ketersediaan SDM kesehatan terbatas salah satunya karena kebijakan moratorium tenaga kesehatan. Kegiatan program membutuhkan SDM yang paham akan fungsi dan pentingnya promosi kesehatan, jika tenaga pelaksana memiliki pemahaman dan kesiapan yang kurang maka akan sulit mencapai tujuan peningkatan derajat masyarakat. ${ }^{16}$

Hasil penelitian ini menunjukkan bahwa selama ini belum ada koordinasi dan komunikasi antara RSUD Noongan selaku rumah sakit PONEK dan puskesmas PONED. Tantangan ke depan dalam pelaksanaan hospital without walls di RSUD Noongan adalah bagaimana menciptakan suatu inovasi program dalam rangka penanganan pasien kebidanan dan kandungan yang emergensi sehingga terjalin komunikasi dan koordinasi antara rumah sakit PONEK dan puskesmas PONED bahkan bisa dalam bentuk peningkatan kapasitas SDM kesehatan puskesmas dari dokter spesialis rumah sakit. Collaborative Improvement PONED-PONEK seharusnya terjadi dalam hal memberikan pelayanan yang komprehensif bagi ibu hamil agar mencegah kematian ibu. Penelitian yang dilakukan oleh Jaya et $\mathrm{al}^{3}$ tentang hubungan SDM, sarana, prasarana, komunikasi PONED-PONEK dan standard operating procedure (SOP) dengan syarat dan persiapan rujukan puskesmas PONED menemukan bahwa koordinasi antara puskesmas dan rumah sakit masih bersifat satu arah, yaitu pihak puskesmas yang menghubungi rumah sakit untuk konsultasi pasien dan rujukan. 
Rumah sakit tidak selalu melakukan umpan balik terhadap kasus rujukan yang dikirim oleh puskesmas. Untuk mewujudkan komunikasi yang baik antara puskesmas PONED dengan rumah sakit PONEK diperlukan peran Dinas Kesehatan untuk memfasilitasi, dengan melakukan koordinasi dan pendampingan. Koordinasi antara petugas PONED dan PONEK di luar rujukan sangat diperlukan, untuk memberikan kesepakatan bagaimana proses rujukan, dan adanya pelatihan penanganan kegawatdaruratan dalam proses rujukan antara petugas PONED dengan petugas PONEK.

\section{SIMPULAN}

Program hospital without walls berpeluang dilaksanakan pada pelayanan kebidanan dan kandungan di RSUD Noongan dengan adanya pelayanan PONEK 24 jam yang memungkinkan kolaborasi dengan puskesmas PONED dalam memberikan penanganan emergensi komprehensif secara terpadu. Program hospital without walls bukan merupakan hal asing bagi rumah sakit karena pada prakteknya sudah dilaksanakan walaupun belum sepenuhnya serta regulasi mendukung program ini.

Tantangan yang akan dihadapi dalam pelaksanaan program hospital without walls pada pelayanan kebidanan dan kandungan di RSUD Noongan meliputi adanya cold case, fasilitas kesehatan dan sumber daya manusia di puskesmas masih kurang serta kolaborasi atau kerja sama PONEKPONED yang belum optimal.

\section{Konflik Kepentingan}

Penulis menyatakan bahwa tidak terdapat konflik kepentingan dalam studi ini.

\section{DAFTAR PUSTAKA}

1. Kementerian Kesehatan RI. Profil Kesehatan Indonesia Tahun 2020. Jakarta: Kementerian Kesehatan Republik Indonesia, 2021.

2. Kementerian Kesehatan RI. Pedoman Penyelenggaraan Pelayanan Obstetri Neonatal Emergency Komprehensif (PONEK) 24 Jam di Rumah Sakit. Jakarta: Direktorat Jendral Bina Pela- yanan Medik, 2008.

3. Jaya ST, Mose JC, Susiarno H. Husin F, Effendi JS. Hubungan sumber daya manusia, sarana, prasarana, komunikasi PONEDPONEK dan SOP dengan syarat dan persiapan rujukan puskesmas PONED. Jurnal Kesehatan Prima. 2019;1(1):4150.

4. Kementerian PPN/BAPPENAS. Kajian Sektor Kesehatan Penguatan Sistem Pelayanan Kesehatan. Jakarta: Kementerian PPN/ BAPPENAS Republik Indonesia, 2019.

5. Ramadhani SN. Studi literatur: analisis faktor penyebab tingginya angka rujukan di puskesmas pada era JKN. Media Gizi Kesmas Universitas Airlangga. 2020; 9(2):57-66.

6. Musruroh, Haq FFS, Sugianto A. Pelaksanaan rumah sakit tanpa dinding. Jurnal Keperawatan. 2020; 12(4):953-68.

7. Pemerintah Daerah Provinsi Sulawesi Utara. Peraturan Gubernur Sulawesi Utara nomor 21 Tahun 2017 tentang Sisten Rujukan Pelayanan Kesehatan di Provinsi Sulawesi Utara. Manado: Pemerintah Daerah Provinsi Sulawesi Utara, 2017.

8. Purwoastuti EES, Walyani. Obstetri \& Ginekologi Sosial Untuk Kebidanan. Yokyakarta: Pustaka Baru Press, 2021.

9. Waworuntu MY, Ratag GAE, Lapian SLHVJ. Peluang dan tantangan hospital without walls pelayanan kesehatan anak. Journal of Public Health and Community Medicine. 2020;1(3):62-9.

10. Sumule ES, Ratag GAE, Posangi J. Penerapan konsep hospital without walls dalam rangka menurunkan angka cold case di pelayanan kesehatan obstetri dan ginekologi di RSUP Ratatotok Buyat [Tesis]. Manado: Universitas Sam Ratulangi; 2021.

11. Wahyuni, Widayati RS, Wulandari R. Study fenomenologi rumah sakit tanpa dinding Di Rumah Sakit Dr. Moewardi Surakarta. Jurnal Ilmiah Kesehatan Keperawatan. 2021;17(1):103-9.

12. RSUD dr Iskak Tulungagung. 2020. Sosok di balik sukses RSUD dr. Iskak menjadi terbaik dunia. [cited 2021 Oct 30]. Available from: https://rsud.tulung agung.go.id/sosok-di-balik-sukses-rsud -dr-iskak-menjadi-terbaik-dunia/.

13. Susyanty AL, Lestary H, Raharni. Pelaksanaan program pelayanan obstetri dan 
540 e-CliniC, Volume 9, Nomor 2, Juli-Desember 2021, hlm. 532-540

neonatal emergency dasar (PONED) di

Kabupaten Karawang. Buletin Penelitian Kesehatan. 2016;44(4):265-78.

14. Kementerian Kesehatan RI. Peraturan Menteri Kesehatan Republik Indonesia tentang Klasifikasi dan Perizinan Rumah Sakit. Jakarta: Kementerian Kesehatan Republik Indonesia, 2020.

15. Oganda $\mathrm{H}$. Analisis manajemen mutu terpadu
Rumah Sakit Umum Daerah Pringsewu. Jurnal Kebijakan dan Pelayanan Publik. 2017;3(2):22-34.

16. Annisa, Jati SP, Budiyanti RT. Analisis pelaksanaan program rumah sakit tanpa dinding (hospital without walls) pada fase pra hospital di RSJD Dr. Amino Gondohutomo. Jurnal Kesehatan Masyarakat. 2021;9(2):274-80. 